\title{
SABERES DA DOCÊNCIA NA EDUCAÇÃO PROFISSIONAL E TECNOLÓGICA: UM ESTUDO SOBRE O OLHAR DOS PROFESSORES
}

José Ângelo Gariglio*

Suzana Burnier* *

RESUMO: Tendo como referência a histórica desregulamentação da docência na Educação Profissional e Tecnológica, além de uma restrita produção científica sobre a matéria, fazemos uma discussão inicial sobre os saberes mobilizados pelos docentes da EP, analisando, a partir das representações dos sujeitos docentes de diversas instituições, os saberes acionados e demandados nas suas atividades educativas e as concepções de formação profissional subjacentes a tais saberes. Autores como Gauthier, Tardif, Lessard, Oliveira e Peterossi ancoram nossas análises, que apontam para a necessidade de se avançar o debate tanto sobre o modelo quanto sobre o lócus da formação desses professores, dando atenção às suas especificidades. Aponta-se para a urgência de definição de políticas de Estado na área: regulamentação do exercício da docência na EP, estratégias de profissionalização, definição de carreiras, salários e avaliação.

Palavras-chave: Saberes da Docência; Educação Profissional; Formação de Professores.

\footnotetext{
* Doutor em Educação pela Pontifícia Universidade Católica (PUC-Rio) Professor da Escola de Educação Física, Fisioterapia e Terapia Ocupacional da Universidade Federal de Minas Gerais (UFMG). E-mail: angelogariglio@hotmail.com

** Professora do Mestrado em Educação Tecnológica e do Programa Especial de Formação Pedagógica de Docentes, Coordenadora do Curso de Especialização PROEJA do Centro de Formação Tecnológica (CEFET-MG). E-mail: suzana@des.cefetmg.br
} 


\section{THE TEACHER KNOWLEDGE BASE CONCERNING TECHNOLOGICAL AND VOCATIONAL EDUCATION (TVE): AN EXPLORATION INTO THE TEACHER'S VIEWPOINTS}

ABSTRACT: Having as its reference the historical teaching de-regulation in technological and vocational education, along with a restricted (rare or scarce) scientific publication on the matter, we carry out an initial discussion concerning the knowledge base mobilized by the TVE teachers. We do this by means of an analysis of: 1) presentations by teachers from several TVE institutions; 2) the knowledge base activated and/or called into demand by these educational activities. Authors like Gauthier, Tardif, Lessard, Oliveira and Peterossi, strengthen (by way of a theoretical base) our analysis, while at the same time making it clear that a debate needs to be launched, as much for the sake of defining the model, as for defining the locus (focal point) in the training that TVE teachers receive. Attention needs to be given to the specificities encountered in providing training for teachers training in this field. The urgent need for the state to define its policies in this area, is also pointed out. For example, there is a need for: 1) the regulation (or standardizing) of TVE teaching practices; 2) strategies to make TVE teaching more professional: defining careers; setting salaries; assessment procedures.

Keywords: Teaching Knowledge; Vocational Education; Teachers' Formation.

\section{A formação de professores da Educação Profissional em questão}

O tema da formação de professores para a Educação Profissional (EP) no Brasil nos remete à história dessa modalidade de ensino, na sua relação com o processo de constituição do sistema educacional no país. É corrente na literatura ${ }^{1}$ a constatação de que o ensino técnico foi criado com o intuito de atender aos interesses e às necessidades produtivas do mundo empresarial. A desarticulação entre a educação regular e a rede de formação profissional paralela gerenciada pelas próprias indústrias - Sistema $S$ - permitiu a essas instituições de formação profissional desenvolver uma mentalidade nitidamente empresarial e incorporar, em sua estrutura e organização, procedimentos eminentemente utilitários (PETEROSSI, 1994).

Soma-se a esse fato outro não menos relevante: o desprestígio da EP frente à educação propedêutica. Esse desprestígio reflete a relação de inferioridade com que o trabalho manual é percebido diante do intelectual numa sociedade marcada pela sociabilidade capitalista. Devido a essa percepção, a formação para os ofícios manuais era oferecida praticamente como caridade para os setores excluídos da sociedade: órfãos, abandonados e "desvalidos da sorte". 
Essa perspectiva reducionista permitiu que se enraizasse uma mentalidade que perdura até os dias de hoje: a noção de que para ser professor de disciplinas ou áreas tecnológicas, mais vale o conhecimento dos conteúdos que se vai lecionar do que propriamente a formação pedagógica (MACIEIRA, 2009). Enquanto a EP ganhava impulso, expandia-se e estruturava-se no país, a formação dos seus professores nunca alcançou o reconhecimento necessário, o que se manifesta na negligência do poder e dos gestores públicos com relação à matéria.

Essa visão é manifesta, por exemplo, no Decreto 2208/97, quando esse dispositivo legal permitiu que a figura do professor fosse substituída pelo instrutor ou monitor. Nessa lógica, a responsabilidade docente fica reduzida ao treinamento ou à capacitação e não considera a complexidade do ato educativo. Como bem lembra Oliveira (2000), não convém aos interesses dominantes que o professor da EP, pela sua influência na formação do trabalhador, seja preparado criticamente para levantar questionamentos na relação ensino $\mathrm{x}$ aprendizado sobre os usos, objetivos $\mathrm{e}$ implicações da tecnologia e, tampouco, sobre a relação capital x trabalho. Daí a opção de priorizar o ensino para, com e da tecnologia, em detrimento de um processo que enfatize a tecnologia a serviço do ensino e o ensino sobre a tecnologia.

Essa visão nos parece ser alimentada, num primeiro nível de análise, por uma história de uma política de não formação (OLIVEIRA, 2005) destinada aos professores que atuam no âmbito da EP. Para essa autora, a formação pedagógica desse professor vem sendo tratada, no país, como algo especial, emergencial, sem integralidade própria e viabilizando propostas de formação aligeirada e superficial, que carece de marco regulatório.

A não percepção dos professores da EP como profissionais da educação é reforçada, num segundo nível, pela carência de estudos sobre a matéria e pela desmobilização da categoria em torno dessa questão. Acompanhando as características gerais das políticas no campo da formação de professores para o ensino técnico, pode-se afirmar, grosso modo, que estudos sobre a temática, bem como a organização dos educadores em torno de debates a respeito, vêm se desenvolvendo de forma descontínua, muito em função de momentos especiais em que essa formação é posta em questão. Assim, não tem sido construída uma cultura de produção acadêmico-científica na área². 
Nesse sentido, o campo científico-tecnológico da formação do professor do ensino técnico vem se mostrando frágil como um campo próprio e estável de conhecimento, resguardada a intensa, extensa e consolidada contribuição que importa das subáreas educacionais do currículo, de trabalho e educação e da própria formação de professores em geral, mas que, também, não vem se ocupando de questões sobre o professor do ensino técnico. Também não há referências frequentes a esse professor e à sua formação, na produção sobre formação de professores construída no interior da Anfope e no debate sobre a política de formação proposta por essa Associação, em suas relações com a política vigente (OLIVEIRA, 2006).

Evidenciando essa situação, por levantamento inicial da produção acadêmica na área da educação, após 1996, constata-se que a questão da formação de professores para o ensino técnico não se encontra contemplada em fóruns de discussão científica da área, como as reuniões anuais da ANPED, de 1996 a 2001 e os Encontros Nacionais de Didática e Prática de Ensino, de 1996 e 1998, mesmo sendo estes últimos verdadeiros encontros de Formação de Professores ${ }^{3}$. No âmbito da produção intelectual de dissertações, teses e livros, encontraram-se apenas duas dissertações (ALVES, 2001; FERREIRA, 2001) e um livro sobre a matéria (PETEROSSI, 1994), no período de 1994 a 2003. Particularmente sobre a formação continuada do professor de ensino técnico, o estudo de Araújo (2004) indica a existência, no período de 1996 a 2004, de apenas um estudo num conjunto de 395 outros sobre formação de professores identificados em várias fontes ${ }^{4}$.

Estudos sobre o estado da arte das pesquisas sobre a formação de professores no Brasil na última década confirmam esse silenciamento da produção intelectual. Entre esses estudos, elencamos os trabalhos de André (2000); André et al. (1999); Brzezinski (2001) Brzezinski et al. (2007) e Ramalho et al. (2002). Em todos eles, manifestou-se uma contundente carência de pesquisas que tratassem da formação de professores da EP.

Essa desatenção da produção intelectual para com o tema da formação de professores da EP vem contribuindo para reforçar a tese de que esses profissionais não pertencem à área da educação, e que a estes cabe, apenas, o domínio dos conhecimentos $\mathrm{da}(\mathrm{s})$ área(s) que pretendem ensinar e a experiência no chão de fábrica. 
Sobre essa questão é importante lembrar que as pesquisas sobre a formação de professores têm forte referência na questão da profissionalização do ensino e do magistério, no esforço dos pesquisadores em definir a natureza dos conhecimentos profissionais que serviriam de base ao exercício da docência. Essa definição ajudaria os governos a projetar padrões curriculares nacionais para a formação de professores, assim como metas a serem alcançadas pelos centros de formação inicial e continuada. Pode-se concluir, portanto, que o pouco interesse do campo da educação em produzir estudos e ações propositivas ao desenvolvimento da formação inicial e continuada de professores da EP tem contribuído ou reforçado a visão de que esses profissionais não pertencem ao campo da educação e que estes podem ser substituídos por instrutores ou monitores. Melhor dizendo, essa omissão ou esse silenciamento presente nas pesquisas contribui para o arrefecimento da luta pela conquista da profissionalização do magistério na EP.

O presente trabalho pretende contribuir para o avanço desse debate, fazendo uma discussão inicial sobre os saberes mobilizados pelos docentes da EP. Partimos de alguns achados advindos do relatório da pesquisa "A formação de professores para o ensino técnico", financiado pelo CNPq e pela Fapemig (2006-2008) . Pretende-se analisar, a partir das representações dos sujeitos docentes de diversas instituições de educação profissional (federais, estaduais e privadas), os saberes acionados e demandados pelos docentes nas suas atividades educativas e as concepções de formação profissional subjacentes a tais saberes. Assim, buscamos analisar que tipos de saberes são demandados por esses professores para o exercício da docência, as formas de acesso a tais saberes e as concepções de formação que tais demandas indicam.

\section{Os saberes docentes em questão}

É corrente nos estudos sobre a formação de professores que os saberes necessários ao ensinar não podem ser reduzidos aos conhecimentos dos conteúdos das disciplinas. Quem ensina sabe muito bem que, para ensinar, é preciso muito mais do que simplesmente conhecer a matéria, mesmo reconhecendo que esse conhecimento seja fundamental. Paralelamente, confundiu-se por muito tempo que as habilidades necessá- 
rias à docência podiam ser resumidas ao talento natural dos professores, ou seja, ao seu bom senso, à sua intuição, à sua experiência ou mesmo à sua cultura. Essas ideias preconcebidas prejudicam o processo de profissionalização do ensino, impedindo o desabrochar de um saber desse ofício sobre si mesmo. É o que os autores denominam de um ofício sem saberes (GAUTHIER et al., 1998)

Simultaneamente, a forma como vem ocorrendo a formação pedagógica dos professores da EP no país, como algo especial, emergencial, sem integralidade própria, não contribuiu para a construção de referenciais e diretrizes mais claras sobre um modelo de formação inicial e continuada que respondesse às especificidades da atuação profissional desses docentes. Essa lacuna tem contribuído para o processo de desprofissionalização dessa atividade docente, isto é, para a visão de que o ofício docente na EP é um oficio sem saberes.

Se compreendermos que o exercício docente na EP constituiu um oficio feito de saberes, o desafio da profissionalização desses professores deve motivar-nos a investigar os saberes próprios do ensino, sendo necessária, para isso, a produção de estudos que consigam revelar as singularidades do contexto profissional no qual os professores encontram-se mergulhados.

Nesta linha reflexiva, a estruturação da análise dos dados da nossa pesquisa está amparada no conceito de epistemologia da prática profissional desenvolvido por Tardif et al. (1999; 2002). Na perspectiva conceitual desses autores, a carreira é um processo de identificação e de incorporação dos indivíduos às práticas e rotinas institucionalizadas dos grupos de trabalho. Os saberes dos professores seriam, portanto, situados, porque construídos em função das situações particulares e singulares de trabalho. É nessa relação específica de trabalho que esses saberes ganham sentido e validade. São, portanto, encravados, embutidos, encerrados em uma situação de trabalho à qual devem atender.

Nessa caracterização, aparece como central a importância da prática profissional dos professores no interior do contexto escolar como referência fundamental para a seleção, a lapidação e a produção de seus saberes pedagógicos. Esse contexto informa e forma os professores, de maneira a organizar seu trabalho e os processos de constituição de seus saberes, rotinas e estratégias de ensino.

Esses saberes apreendidos e incorporados em contextos situados e singulares de trabalho são definidos como saberes da experiência 
profissional (TARDIF, 1999; 2002). São saberes fundados no trabalho cotidiano dos educadores e no conhecimento do seu meio. São inventados da experiência e por ela validados e revalidados, incorporando-se à vivência individual e coletiva sob a forma de habitus, rotinas e de habilidades de saber-fazer e saber-ser.

A noção de saber, aqui proclamada, diferentemente do conhecimento científico, encerra um sentido mais amplo, uma vez que englobaria os conhecimentos, as competências, as habilidades (ou aptidões) e as atitudes, isto é, aquilo que muitas vezes é chamado de saber, saber-fazer e saber-ser (TARDIF, 2002).

Assim, o corpo docente, na impossibilidade de transpor linearmente para a sua prática docente os saberes das disciplinas, do currículo e da formação profissional, constrói intermediações e traduções, que, por sua vez, terminam influenciando o próprio professor, levando-o a produzir outros saberes por meio dos quais pode compreender e dominar sua prática. Esses saberes constituem os fundamentos da competência dos professores, julgando, com base neles, sua formação anterior, a pertinência e a validade das reformas introduzidas por políticas educacionais nos programas ou nos métodos, assim como na resolução de problemas e conflitos advindos do exercício profissional. Enfim, é graças aos saberes da experiência que os professores concebem os modelos de excelência profissional em sua profissão (TARDIF et al., 1999; TARDIF, 2002; GAUTHIER, 1998)

Os esforços de diversos estudiosos em definir os conteúdos dos saberes da base profissional dos professores ainda trazem consigo indefinições sobre o conceito de "saber". Surgem estes questionamentos: os professores desenvolvem e/ou produzem verdadeiramente "saberes" resultantes de sua prática? Caso positivo, quando, como, sob que forma? Tratam-se verdadeiramente de saberes? Não seriam antes crenças, certezas não fundamentadas ou habitus, esquemas de ação e de pensamento interiozados no âmbito da socialização profissional?

Essas questões estão no centro dos debates que circundam o tema dos saberes docentes. Esse debate traz no seu núcleo influências das contribuições dos estudos de Schön (2000) sobre o profissional reflexivo. Esse autor, ao desenvolver os conceitos de "conhecer na ação", de "reflexão na ação" e de "reflexão sobre a ação", procura demonstrar como os práticos, durante suas atividades profissionais, desenvolvem processos 
reflexivos que seriam dotados de características sui generis em relação à lógica aplicacionista e linear das práticas reflexivas próprias do modelo acadêmico/científico. Segundo suas pesquisas com diversos grupos profissionais, os práticos desenvolveriam, em suas atividades laborais, a capacidade de refletir na ação, ou seja, outra forma de reflexão que seria a imediata significação para a ação, o que o autor denomina de reflexão na ação. Nela, o repensar de algumas partes de nosso conhecer-na-ação leva a experimentos imediatos e a mais pensamentos que afetam o que fazemos - na situação em questão e talvez em outras que possamos considerar como semelhantes a ela. Para ele, a reflexão na ação é um processo que podemos desenvolver sem que precisemos dizer o que estamos fazendo. São ações que os práticos não sabem descrever com precisão, e que evidenciam a existência de um saber que se constrói no próprio fazer. Esse conhecimento tácito parece estar implícito nos modelos de ação dos profissionais, adquiridos mediante o exercício de determinada atividade.

Sermos capazes de refletir na ação é diferente de sermos capazes de refletir sobre a nossa reflexão na ação, de modo a produzir boa descrição verbal dela. Isso porque, muitas vezes, a rotina e a repetição fazem o conhecimento prático tornar-se tão espontâneo que os profissionais não mais refletem sobre o que estão fazendo. É com base nessas considerações que Schön (2000) advoga a ideia da reflexão como elemento fundamental para o desempenho da atividade profissional. Por meio da reflexão, é possível criticar a compreensão tácita subjacente à avaliação e ao julgamento da situação. É possível, ainda, chegar ao questionamento das estratégias e teorias implícitas em um modelo de comportamento ou em uma linha de desempenho.

Sob essa perspectiva da reflexão sobre a ação, os professores, ao ser questionados sobre suas práticas, seriam capazes de explicar, com argumentos claros, quais os propósitos e as finalidades de suas estratégias de ensino. Assim, saber qualquer coisa não é somente fazer um julgamento verdadeiro sobre o que se faz (um fato ou uma ação), mas é também ser capaz de estabelecer as razões pelas quais esse julgamento é verdadeiro. O saber do professor não residiria no sujeito, mas nas razões públicas que esse sujeito apresenta para tentar validar, em uma argumentação ou por meio dela, um pensamento, uma proposição, um ato, um meio. A argumentação, portanto, seria o lugar do saber. (TARDIF el al., 1999) 
A ideia de racionalidade aqui defendida se refere a um saber que se compreende e que serve de base para a estruturação dos argumentos do professor. Seriam precisamente esses argumentos que constituiriam a nossa episteme cotidiana (TARDIF, 2002). Na vida cotidiana, nossos atos e nossos discursos apoiam-se em saberes que fornecem um quadro de inteligibilidade e de sentido às nossas empreitadas. Para esses autores, a ideia de exigência de racionalidade não remete a um ato hiper-racional, cuja ação e cujo discurso decorreriam de um conhecimento completo da situação. Ao contrário, essas exigências seriam tributárias de uma racionalidade fortemente marcada pelo saber social, saber em comum e partilhado por uma comunidade de atores, saber prático que obedece a inúmeras lógicas de comunicação e que está enraizado em razões, motivos e interpretações lógicas de comunicação e também em razões, motivos e interpretações que recorrem a inúmeros tipos de julgamento.

Se a compreensão acerca dos saberes que fundamentam o exercício da docência é tarefa que ainda se coloca para a pesquisa na educação básica, muito mais incipiente se encontra tal reflexão em relação à docência na Educação Profissional. Nessa modalidade educativa, a docência, além de muito menos investigada, apresenta toda uma série de peculiaridades: é exercida por pessoas que foram formadas em outras áreas, em geral técnicas, distantes do campo da educação e que, raras vezes, tiveram acesso a algum tipo de formação pedagógica anterior ao exercício da docência. Além disso, essas pessoas muitas vezes possuem experiências profissionais nas áreas técnicas que constituem sua visão de mundo e de profissional da área, o que impactará sua atuação na formação dos alunos.

Ao entendermos que o ofício docente é feito de saberes, o desafio da profissionalização dos docentes da EP deve motivar-nos a investigar quais seriam os saberes da base profissional desses professores, sendo necessária, para isso, a produção de estudos que consigam revelar as características desses saberes, bem como o complexo contexto de trabalho no qual esses professores encontram-se mergulhados. É o que passamos a tratar, instados pela urgência da definição de modelos de profissionalização e de formação de professores dessa categoria profissional. 


\section{Saberes da docência na Educação Profissional}

O nosso estudo teve o recurso da entrevista como técnica de coleta de dados central. Foram entrevistados 19 professores do Ensino Técnico, sendo nove docentes de instituições da Rede Federal de Educação Tecnológica de vários estados brasileiros, cinco da rede particular e outros cinco de uma escola da rede estadual de educação de Minas Gerais. Todos os docentes lecionam disciplinas das áreas tecnológicas e a maioria deles tem mais de cinco anos de experiência com a docência na EP, possuindo, portanto, acúmulo de experiências nessa atividade.

Ainda sobre nossa opção metodológica de priorizar o uso da entrevista, vale lembrar o instigante debate estabelecido por Tardif e Lessard (1999) sobre a conceituação do que eles defendem como sendo o "saber". Para eles, saber qualquer coisa ou fazer qualquer coisa de forma racional é ser capaz de responder às questões - "por que você fez isso?", "por que você diz isso?"-, oferecendo razões, motivos e justificativas suscetíveis de servir de validação ao discurso ou à ação.

Nesse espírito, não basta fazer bem uma coisa, é preciso também que o ator saiba por que faz as coisas de certa maneira. Os autores supracitados levantam essa questão com o objetivo de evitar que as pesquisas sobre os saberes docentes continuem a ser vítimas do que eles chamam de "excesso etnográfico", ou seja, em que tudo é tomado como saber: ideologias, crenças, sentimentos, emoções, intuição, habitus e rotinas. E perguntam: "Se tudo é saber, para que então estudar o saber?" Para eles, os saberes docentes seriam definidos como todos os atos e discursos nos quais os práticos são capazes de fornecer as razões que os motivam.

É visão corrente da parte do professor do Ensino Técnico e no interior da própria área, quanto à natureza da função docente, de que, para ser professor, o mais importante é ser profissional da área relacionada à(s) disciplina(s) que se vai lecionar. O professor do Ensino Técnico não é concebido como um profissional da área da educação, mas um profissional de outra área e que nela também leciona. Por sua vez, as agências formadoras também encontram dificuldades na definição dos currículos para os cursos e programas de formação desse professor, considerando-se, sobretudo, a variada gama de disciplinas dos cursos técnicos, os diferentes setores da economia aos quais se referem, as características do aluno e 
do próprio quadro docente responsável pela formação desse futuro professor (OLIVEIRA, 2006).

Ao analisarmos os discursos dos professores pesquisados, um primeiro aspecto importante a se notar é a relação entre o tipo de estabelecimento de ensino em que o docente atua e a construção das concepções de docência edificadas pelos professores e seus impactos sobre os tipos de saberes demandados acionados em sua prática cotidiana. Como investigamos docentes de instituições de naturezas diferentes, pudemos constatar algumas particularidades. Evidenciou-se, por exemplo, que uma diversidade de visões associada ao modelo de instituição já começa a ser construída no processo de contratação do docente. Nas instituições federais, em geral, é exigida formação em pós-graduação stricto sensu, o que faz com que os docentes contratados tenham formação mais sólida no campo da pesquisa e menor experiência nas empresas. No extremo oposto, nas escolas privadas, as contratações tendem a priorizar aqueles que possuem experiência no mercado, com maior foco nos aspectos práticos tanto da aprendizagem quanto do exercício profissional.

Assim, nas instituições públicas, há maior demanda, por alguns docentes, de tempos e espaços para a reflexão coletiva, para o enfrentamento dos desafios pedagógicos e para o aprofundamento dos fundamentos teóricos da prática pedagógica, especialmente no que se refere à necessidade de formar alunos reflexivos e criativos, atributos fortemente valorizados na cultura científica, especialmente nas escolas federais. ${ }^{6}$

Certo, um enfoque na parte prática, dos processos de fabricação e compras, mas também um enfoque, talvez 50\% na parte da imaginação, do que a pessoa pode oferecer de novo e do que ela não pode atender ao modelo pré-concebido. Então ele tem que ser criativo, tem que se posicionar, encontrar novas soluções, a possibilidade que ele tem de oferecer para o mundo, como um todo, inovações, coisas que não estão colocadas na mesa boje, mas ele estar com a mentalidade também sempre aberta.(PRF1)

$\mathrm{Na}$ instituição pública estadual, que atende alunos de periferia, essa condição parece demandar dos professores maior reflexão e capacidade de interlocução com questões sociais e políticas de diferentes ordens. Atendendo alunos cuja base escolar é muitas vezes precária, oriundos de famílias excluídas dos benefícios materiais e culturais gerados pela sociedade, esses professores enfrentam maiores contradições em suas salas de aula e demandam saberes que os habilitem a lidar com tais questões de 
maneira mais eficaz. Parece haver maior sensibilidade pedagógica para com os educandos, entendidos não apenas como sujeitos epistêmicos, mas, também, como sujeitos sociais e culturais.

Você aprender que você recebe um aluno e sempre, por trás daquele aluno ali, tem toda uma bistória e que às vezes a gente não conbece e faz um pré-julgamento da pessoa e isso aí pode atrapalhar a formação dessa pessoa. (PRE1)

Nesses discursos, os professores expressam, também, que a formação para a docência apresenta-se frágil ou incipiente de saberes pedagógicos que os ajudem a construir uma intervenção profissional para além das fronteiras estreitas do treinamento e da qualificação profissional. A angústia manifesta na fala do professor supracitado revela que ele reconhece ser necessário possuir conhecimentos sobre os sujeitos da educação. Esse professor relativiza, portanto, o ideário neoliberal presente nos discursos educacionais, conservadores, na EP, que preconizam a ideia de que aos docentes dessa modalidade de ensino mais vale o conhecimento dos conteúdos a serem lecionados do que, propriamente, a formação pedagógica. Esse discurso é o mesmo que ignora ou secundariza os saberes sobre os educandos. Os discursos dos professores que atuam com alunos pertencentes a segmentos excluídos destacam o fato de que a proximidade a esses alunos dá à docência novas dimensões. Seu conhecimento aprofundado, científico e sistemático pode ser uma precondição para avançarmos em tratos mais profissionais no magistério da EP. Como bem lembra Arroyo (2004), o grau do profissionalismo na docência passa pelo conhecimento sistematizado, científico, que tivermos dos educandos, de seus processos mentais, sociais e culturais, éticos ou estéticos.

Nas instituições públicas, parece haver consenso sobre a importância da licenciatura ou de algum tipo de formação pedagógica inicial para preparar os docentes da EP. Vários professores explicitaram suas dificuldades dentro da sala de aula ou mesmo nas tarefas anteriores, de planejamento e organização dos cursos, atribuindo-as à falta de preparação pedagógica prévia.

O que eu conbeço de professor na área de Ensino Técnico, normalmente são um engenheiro, um biólogo que não tem formação nenhuma na área de Ciências Humanas, pedagógicas, principalmente, e que de repente você se vê professor. O aluno sofre. Às vezes você nem sabe como você aprendeu um assunto, você sai imitando os professores que você teve. (PRF2) 
Você vai aprendendo na prática, apanhando, perguntando, no tranco... (PRP1)

A formação exclusiva numa área de conbecimento dada pelo bacbarelado não responde a determinadas questões que o professor precisa lidar com elas, particularmente as relativas ao processo de formação de conbecimento. (PRE2)

Entretanto, as licenciaturas não são valorizadas a priori: há diversas críticas aos tipos de saberes ali trabalhados e à sua distância em relação à prática docente concreta. Mesmo assim, houve quem defendesse que a realização de formação pedagógica fosse critério de ingresso ou de progressão na carreira, de forma a assegurar que todo professor da EP receba tal formação. Em defesa da formação pedagógica, são inúmeros os conhecimentos demandados pelos professores da EP: teorias do conhecimento, epistemologia e história da ciência e da técnica, desenvolvimento da criatividade, ensino por projetos, a questão da motivação do jovem, a contextualização do ensino, a montagem de currículos, o estudo das políticas educacionais e a relação das políticas de Ensino Profissional com o contexto geral. Além disso, os docentes da EP das escolas públicas ainda demandam os saberes que os capacitem a preparar aulas, acompanhar as turmas, preparar recursos didáticos, executar as atividades anteriores e posteriores às aulas, a planejar, desenvolver e avaliar trabalhos interdisciplinares, a controlar a atividade dos alunos e assegurar a disciplina em sala de aula e a ter desenvoltura na comunicação oral.

O relato a seguir, de um professor de uma das escolas técnicas da Rede Federal de Ensino, destaca a relevância de um curso de formação pedagógica para sua atuação como docente da EP:

Eu fiquei mais sensivel às questões de ensino: como tornar, para o aluno, interessante, uma coisa dificil. Como isso pode mudar a abordagem dele como aluno na sua disciplina? Encantar o aluno. Os recursos áudio visuais. Como que o projeto, por exemplo, aqui, eu e o professor $x$, que atua lá no CEFET e outro professor, nós experimentamos o ensino por projeto, para contextualizar o conbecimento do aluno. Certas abordagens, você, que é muito técnico, não tem essa visão, essa sensibilidade. (PRF1)

A questão da relação com a juventude aparece de forma bastante destacada: lidar com adolescentes, assegurar o clima de produção em sala de aula, motivar os alunos são tarefas para as quais os professores demandam fortemente por saberes de apoio. 
A gente mexe com alunos nessa faixa etária, de 15 a 18 anos, a gente precisa ter uma formacãa melhor, eu acho que tem que ter uma formacão melhor na área de psicologia. Você não tem certos fundamentos que preencham satisfatoriamente. (PRE1)

Já nas instituições privadas, a tônica parece recair sobre saberes mais pragmáticos, tanto aqueles que possibilitem uma formação diretamente associada às demandas do mercado, quanto os saberes relacionados às intervenções cotidianas na sala de aula: saber se colocar diante das turmas, lidar com os jovens de hoje com seus celulares e $i$-Pods, linguagens adequadas para a sala de aula (verbais, corporais, textuais), técnicas de ensino e avaliação, técnicas de uso do quadro-negro e de outras tecnologias de ensino.

O que poderia melhorar é exatamente no auxilio didático, na questão do data show, que hoje em dia não se discute mais o que há de melhor, você tem a facilidade de preparar em casa uma aula diferente, com um visual melhor do que dentro de sala, que às vezes você vai tentar mostrar uma coisa e se você não tem esse quadro aqui, se você tem um data show, você pode mostrar isso aqui por diversos lugares. (PRP1)

É interessante notar que, em todas as instituições investigadas, os saberes oriundos da produção, da empresa, do mercado são profundamente valorizados pelos professores da Educação Profissional. Os que atuam ou já atuaram na indústria avaliam tais saberes como de grande utilidade nas salas de aula dos cursos técnicos. Por meio desses saberes, os conhecimentos apresentados aos alunos adquirem vida com exemplos práticos de situações profissionais concretas que eles enfrentarão no mundo do trabalho. Outra contribuição específica desse tipo de saber é sua atualização tecnológica, uma vez que as indústrias, por exigência da competição de mercado, costumam atualizar-se tecnologicamente, enquanto que as escolas e mesmo as universidades, onde são cursados os mestrados e doutorados, dificilmente conseguem acompanhar o ritmo de atualização tecnológica do mercado. Uma terceira contribuição atribuída aos saberes do mercado refere-se à inclusão, nos cursos, de questões relativas à dinâmica do cotidiano de trabalho, à organização cotidiana da produção, às relações sociais de produção e ao conjunto de saberes e habilidades correlatas a tais questões. Dessa forma, até mesmo mestres e doutores que lecionam nas escolas federais de EP ressentem-se da falta de mais aproximação com a indústria, nos sentidos antes descritos: da rela- 
ção da teoria com a prática, de sua atualização tecnológica e do conhecimento do cotidiano da organização do trabalho na empresa.

Nos depoimentos dos professores sobre o fazer pedagógico na escola, há ênfase nos aspectos propriamente didáticos (PIMENTA, 2003). Para Pimenta (2003), a didática trata das finalidades do ensinar do ponto de vista político-ideológico (da relação conhecimento e poder, conhecimento e formação humana, direitos, igualdade, felicidade, cidadania), psicopedagógicos (da relação conhecimentos e desenvolvimento das capacidades de pensar e sentir, dos hábitos, atitudes, valores) e os propriamente didáticos (organização dos sistemas de ensino, de formação, das escolas, da seleção de conteúdos de ensino, de currículos e organização dos percursos formativos, das aulas, dos modos e formas de ensinar, da avaliação, da construção de conhecimento). Essa interpretação confirma, de certa maneira, a reflexão feita por Tanguy (1986), de que o Ensino Técnico, fundamentalmente transmissor de conhecimentos imediatamente úteis e práticos, é esvaziado de um saber social de caráter humano, deslocando-o, assim, do contexto político, econômico e social.

A valorização dos saberes advindos da experiência no mercado chega a um ponto em que, para alguns docentes, o domínio desses saberes é suficiente para assegurar o sucesso no ensino, ainda que não seja o caso da maioria.

[é importante para o professor] primeiro, que ele tenha a formação técnica, que tenha uma bagagem técnica, teórica e é importante que ele tenha uma bagagem prática. Por exemplo, eu vou ser um mecânico de automóveis, eu vou dar aulas sobre manutenção de veículos, eu tenho que saber consertar um carro. (PRP2)

É muito difícil você pegar um engenheiro recém-formado que consiga dar uma aula legal. Muito dificil. Geralmente, quem tem uma determinada experiência dentro daquela, uma vivência profissional vai ter condições e recursos pra ele dar exemplos porque não exige melhor ensino do que o exemplo. (PRP1)

Os depoimentos dos entrevistados evidenciam que os professores estariam apontando para o fato de que, na EP, os saberes disciplinares (conhecimentos tecnológicos) e a experiência nas empresas trazem consigo conteúdos formativos potentes e suficientes ao exercício da docência. Segundo a percepção de parte significativa dos docentes entrevistados na pesquisa, esses conhecimentos ganhariam o status de saberes-mestres. 
Nenhum saber é por si mesmo formador. Os mestres não possuem mais saberes-mestres, cuja posse venha garantir sua mestria: saber alguma coisa não é mais suficiente, é preciso também saber ensinar. $O$ saber transmitido não possui, em si mesmo, nenhum valor formador; somente a atividade de transmissão lhe confere esse valor. Em outras palavras, os mestres assistem a uma mudança na natureza da sua mestria: ela se desloca dos saberes para os procedimentos de transmissão dos saberes. (TARDIF, 2002, p. 43)

Entretanto, é importante ressaltar que os saberes ligados ao trabalho mostram-se restritos às demandas das empresas para a formação de mão de obra. Não se encontram, no campo das representações desses docentes, referências a outros aspectos da formação para o trabalho, como informações e discussões sobre direitos trabalhistas, organização sindical ou de outros movimentos sociais ou sobre a tão difundida ideia de meritocracia. Poucos docentes mencionam a necessidade de se articular a formação para o trabalho com uma formação mais ampla para a felicidade, a expressão, a realização pessoal ou ainda para a vida coletiva. Os saberes oriundos das lutas dos trabalhadores, dos movimentos sociais ainda não se fazem presentes nas representações desses professores sobre os saberes da docência. Quando se avança da formação estrita para as demandas do mercado, a referência fundamental é o campo da ciência e do desenvolvimento cognitivo mais amplo, o que, não sendo pouco, entretanto, não é tudo, quando se trata da formação de jovens, de cidadãos.

Os saberes demandados (e os não demandados) pelos docentes da EP apontam para a necessidade urgente de se construir sua profissionalização. Os professores ressentem-se da falta de um corpus de conhecimentos que balize suas escolhas dentro e fora da sala de aula, nas relações com os alunos, com os colegas, com outras instituições, com o mundo do trabalho e com a sociedade em geral. Obviamente, ficou evidenciado que o modelo institucional é definidor importante das concepções docentes, uma vez que estabelece o campo de possibilidades no qual os professores constroem suas práticas e os saberes da experiência. Assim sendo, a total ausência de regulamentação da profissão docente na EP acarreta que os professores se vejam à mercê das contingências institucionais, num modelo social em que a iniciativa privada vem, historicamente, se fazendo presente na formação de trabalhadores sob a perspectiva estrita do capital. 


\section{Considerações finais e conclusões}

Para construir as considerações finais deste artigo, tomamos como referência o modelo tipológico criado por Tardif (2002) para identificar e classificar os saberes profissionais dos docentes. Nesse modelo, busca-se compreender o pluralismo do saber da base profissional dos professores, relacionando-se com os lugares nos quais os próprios professores atuam, com as organizações que os formam e/ou nas quais trabalham, com seus instrumentos de trabalho, as fontes de aquisição desse saber e seus modos de integração no trabalho docente. Nessa perspectiva, seriam cinco os tipos dos sabres docentes: os saberes pessoais (a família, o ambiente da vida, a educação no sentido lato); os saberes provenientes da formação escolar anterior (da escola primária e secundária); os saberes provenientes da formação profissional para magistério (a formação inicial, os estágios, a formação continuada para o exercício do magistério), os saberes advindos dos programas e livros didáticos usados no trabalho e os sabres provenientes de sua própria experiência na profissão, na sala de aula e na escola.

Os dados da nossa pesquisa nos permitem discutir, entre outras questões, as concepções que esses docentes têm sobre sua formação inicial e continuada para o exercício da docência na EP. Os nossos sujeitos de pesquisa evidenciam alguma das especificidades da formação para lecionarem nessa modalidade de ensino. Eles ressaltam a importância das experiências desse profissional no mercado, o que confirma o argumento, consolidado na área, de que há outros saberes, além dos pedagógicos, que constituem a formação docente para o Ensino Técnico. A isso chamamos saber-mestre, saber esse que seria capaz de fornecer um repertório variado de conhecimentos específicos (tecnológicos) ${ }^{7}$ e habilidades práticas passíveis de serem transmutáveis ao contexto da aprendizagem tipicamente escolar e que seriam centrais ao exercício da docência na EP. Esses saberes experienciais, mesmo não sendo apreendidos na ambiência do trabalho docente na escola e na sala de aula, constituem elemento fundante ao processo de socialização profissional desses professores. Os saberes, o saber ser e saber fazer desses professores mostram-se fortemente marcados pela experiência profissional no universo empresarial. Como bem lembra Dubar (1997), o espaço de reconhecimento das identidades é inseparável do espaço de legitimação dos saberes e das competências associa- 
das às identidades. A transação objetiva entre indivíduos e as instituições é, antes de tudo, aquela que se organiza a volta do reconhecimento e do não-reconhecimento das competências, dos saberes e das imagens de si que constituem os núcleos duros das identidades reivindicadas.

Nesta discussão, parece-nos importante ressaltar que esses saberes poderiam ser tomados como saberes de ordem pessoal, constituídos em determinado universo de socialização profissional (o mundo do trabalho) e que são interiorizados pelos professores da EP, de forma a gerar um conjunto de conhecimentos, condutas, competências, crenças e valores que são reatualizados e reutilizados, em alguma medida, de maneira não reflexiva, mas com grande convicção, na prática de seu ofício docente na escola. Nessa linha, a percepção dos professores sobre o que seria a formação inicial e continuada para o exercício da docência na EP mostrouse distante da formação pedagógica e fortemente vinculada à experiência profissional no mercado de trabalho e em experiências de formação em cursos, eventos, palestras que tratam de temas relacionadas à área específica (tecnológica).

Atrelada ainda a essa dimensão da experiência, os professores também colocam em relevo a experiência na sala de aula como um dos elementos constitutivos de sua identidade profissional. O que fica ressaltado, nos discursos dos nossos sujeitos de pesquisa, é a centralidade da relação que estabelecem com os alunos e o peso que estes sujeitos têm na constituição do "eu profissional". O saber experiencial construído no território da prática docente parece estar ligado a determinado tipo aprendizagem que é fundante à profissão docente: essa atividade profissional não é exercida por um objeto, sobre um fenômeno a ser conhecido ou uma obra a ser produzida. Ela é realizada concretamente, numa rede de interações com outras pessoas, num contexto onde o elemento humano é determinante e dominante e onde estão presentes símbolos, valores, sentimentos, atitudes que são passíveis de interpretação e decisão e que, geralmente, possuem caráter de urgência. Essas interações são mediadas por diversos canais: discursos, comportamentos e maneiras de ser. Elas exigem do professor não um saber sobre um objeto de conhecimento nem um saber sobre uma prática e destinado principalmente a objetivá-la, mas a capacidade de se comportarem como sujeitos, como atores e de serem pessoas em interação com pessoas. Tal capacidade é geradora de certezas particulares, pelo docente, de sua própria capacidade de ensinar e de atingir bom 
desempenho na profissão (TARDIF, 2002). Entendendo que os objetoscondições de trabalho dos docentes da EP não têm o mesmo valor e que obedecem, portanto, uma hierarquia, pois seu valor depende das dificuldades que apresentam em relação à prática, pode-se afirmar que estar diante dos alunos e interagir com eles em situações de ensino constitui a parte de maior status no processo da aprendizagem docente. É nessa relação que são construídos e validados seus saberes docentes.

Sobre essa questão vale citar o estudo realizado por Burnier et al. (2007) acerca da história de vida de professores da EP. A autora chama a atenção para o fato de que, no caso da Educação Profissional, fica evidenciado que as origens sociais semelhantes, com experiências familiares e de vida bastante próximas, dos docentes identificam os alunos, assim como a si mesmos, como "lutadores", à procura de uma oportunidade, e veem, no mundo do trabalho, o principal (ou o possível) canal de acesso a melhores condições e vida. O magistério na Educação Profissional significa uma oportunidade de contribuir para a melhoria de vida de seus alunos, melhoria esta que é, na classe trabalhadora, valor central de orientação de vida. Com isso, o significado do trabalho docente consegue extrapolar, para esses sujeitos, sua dimensão meramente instrumental, e banhase de sentidos expressivos, tão característicos das atuais demandas dos trabalhadores.

Tomando como pressuposto que os objetos-condições de trabalho são objeto de conhecimento que constituem a própria prática docente e que só se revelam através dela, nosso estudo mostrou que, segundo a percepção dos nossos docentes da EP, os saberes pedagógicos ocupam uma posição de menor status na hierarquia dos saberes necessários a ensinar. Tal fato pode ser explicado pelas fortes limitações impostas pela falta de acesso a um debate mais qualificado sobre a função social da escola e da Educação Profissional, informados pelo debate de cunho crítico que busca estabelecer relação entre Educação Tecnológica, Ensino Técnico e formação humana. Todavia, alguns dos docentes entrevistados reafirmam a importância do saber pedagógico e apontam informações de que se sentem carentes de conhecimentos e competência para agir em situação de ensino e esperam ter mais oportunidades de se desenvolver nesse campo de saber.

A dificuldade dos professores da EP em localizar e reconhecer a relevância dos saberes pedagógicos em sua prática pedagógica cotidiana 
na escola se desdobra em outra questão não menos importante. As dificuldades epistemológicas na construção de propostas didático-pedagógicas para a Formação de Professores para o Ensino Técnico relativas a conteúdos e formas de pedagogização do saber técnico em saber escolar, para efeito de seu ensino nos cursos de formação de futuros professores para a área. Um fator fundamental, nesse aspecto, é, exatamente, a falta de estudos e práticas sobre a matéria. Todo esse contexto é agravado pelas dificuldades técnicas na definição, em dado curso de Formação de Professores para o Ensino Técnico, das disciplinas em que o futuro professor se formará. E isso por conta da gama variada de habilitações/disciplinas técnicas em que é possível se habilitar como professor, em cada uma das mais de vinte Áreas Técnicas do setor produtivo e de serviços, definidas pelas próprias orientações curriculares oficiais.

Os achados centrais da nossa pesquisa apontam para o fato de que os processos identitários relacionados à docência na EP mostram-se fortemente informados por espaços sociais outros, para além dos muros do campo pedagógico, que articula, numa teia de significados, hábitos e valores oriundos dessa diversidade de experiências. Tal constatação reforça a tese de que a profissionalidade docente comporta uma dimensão social fundamental e se insere em relações sociais marcadas pela negociação com um tipo de trabalho específico, com seus conteúdos, com suas exigências próprias, com suas finalidades situadas e com suas estratégias de controle e autonomia (LESSARD et al., 2003). Não há apenas uma cultura docente comum ao conjunto dos professores, mas, sim, culturas profissionais produzidas no processo de interação cotidiana com tipologias de trabalho docente específicas, processo esse estruturado por diversas condições e contratos sistemáticos - ordens escolares, setores de ensino, ambientes peculiares de ensino, campos de ensino, estabelecimentos de ensino e ambientes socioeconômicos da região, nos quais os docentes exercem sua profissão e constroem seus sabres profissionais. Os saberes profissionais construídos pelos nossos depoentes advêm, portanto, de sujeitos concretos que assumem sua prática, baseando-se em seus próprios significados. Ou seja, profissionais que possuem conhecimentos e um saber-fazer proveniente de uma ação docente particular, com base na qual eles a estruturam e orientam.

O nosso estudo teve como de um de seus objetivos centrais mostrar que o ofício docente na EP é um ofício feito de saberes. Ao con- 
firmar essa hipótese, demos uma pequena contribuição ao avanço do processo de profissionalização desses professores, mostrando algumas das características dos saberes próprios do ensino dos professores da EP. Num momento em que se fazem urgentes a discussão e a definição de uma política de formação inicial e continuada de professores para a Educação Profissional, inexistente no país, acreditamos que os impasses e as potencialidades vividas por esses docentes e aqui apontados possam constituir-se em pistas para a construção de tais políticas. 


\section{Referências}

ALVES, Israel Gutemberg. Professores e sociedade: 2000 anos de (des)sintonia na historia e na formação de professores no Centro Federal de Educação Tecnológica de Minas Gerais. 2001. 217p. Dissertação (Mestrado em Tecnologia) - Centro Federal de Educação Tecnológica de Minas Gerais, Belo Horizonte, 2001.

ANDRÉ, M; SIMÕES, R. H. S.; CARVALHO, J. M.; IRIA, B. Estado da arte da formação de professores no Brasil. In: Educação e Sociedade, [S.1.], n. 68, p. 299-309, 1999. ANDRÉ, Marli. A pesquisa sobre formação de professores no Brasil - 1990-1998. In: CANDAU, V. (Org.). Ensinar e aprender: sujeitos, saberes e pesquisa. Rio de Janeiro: DP\&A, 2000. p. 83-100.

ARAÚJO, Tânia Márcia Fernandes de. A formação continuada segundo professores do ensino técnico. 2004. 168p. Dissertação (Mestrado em Tecnologia) - Centro Federal de Educação Tecnológica de Minas Gerais, Belo Horizonte, 2004.

ARROYO, Miguel G. Imagens quebradas: trajetórias e tempos de alunos e mestres. Petrópolis, RJ: Vozes, 2004.

BRZEZINSKI, Iria. Análise dos trabalhos do GT Formação de Professores: o que revelam as pesquisas do Período 1992-1998. Revista Brasileira de Educação, Rio de Janeiro, n. 18, p. 82-100, 2001.

BRZEZINSK, Iria et al. Estado da arte da formação dos professores no Brasil. In: Educação e Sociedade, [S.1.], ano XX, n. 68, 1999.

BRZEZINSKI, I.; GARRIDO, Elza. Trabalho docente: mapeando a pesquisa em teses e dissertações brasileiras. Educação \& Linguagem, v. 1, p. 60-81, 2007.

BURNIER, Suzana et al. Histórias de vida de professores: o caso da educação profissional. Rev. Bras. Educ. [online]. v. 12, n. 35, p. 343-358, 2007.

COELHO, Suzana Lanna Burnier. Repensando um projeto de educação tecnológica referenciado na formação do cidadão-técnico: algumas reflexões para a formulação de novas propostas educativas. Educação \& Tecnologia, Belo Horizonte, n. 2, p. 52-56, jul.-dez. 1997.

CUNHA, Luiz A. Ensino Médio e Ensino Técnico na América Latina: Brasil, Argentina e Chile. Cadernos de Pesquisa. São Paulo: FCC, n. 111, p. 47-70, dez. 2000.

DUBAR, Claude. A socialização: construção das identidades sociais e profissionais. Porto: Porto Editora, 1997.

FERREIRA, Maria Lúcia. Programa especial - a contribuição da UTRAMIG: da qualificação técnica profissional à formação docente. Os sujeitos da educação à luz dos pressupostos do agir comunicativo no pensamento de Habermas. 2001. Dissertação (Mestrado em Tecnologia) - Centro Federal de Educação Tecnológica de Minas Gerais, Belo Horizonte, 2001.

FRIGOTTO, G.; CiAVATTA FRANCO, M. A.. Programa de Expansão e Melhoria do Ensino Técnico: Expressão de um conflito de concepções de educação tecnológica. Revista Contexto \& Educação, Ijuí, v. 7, n. 104, p. 38-48, jan.-fev. 1992.

FRIGOTTO, Gaudêncio; CIAVATTA, Maria. Educação básica no Brasil na década de 1990: subordinação ativa e consentida à lógica do mercado. Educação e Sociedade, [S.1.], 2003, v. 24, n. 82 p. 93-130. Disponível em:

http://www.scielo.br/scielo.php?script=sci_arttext\&pid=S0101- 
73302003000100005\&lng=en\&nrm=iso. Acesso em 23 mai. 2011.

GARCIA, N. M. D.; LIMA FILHO, D. L. Politecnia ou educação tecnológica: desafios ao ensino médio e à educação profissional. In: REUNIÃO ANUAL DA ANPED, 27, 2004, Caxambu. Trabalhos apresentados. Caxambu, MG, 2004. Disponível em: $<$ http://www.anped.org.br/reunioes/27/diversos/te_domingos_leite.pdf $>$. Acesso em: 19 Dez. 2009.

GAUTHIER, C.; MARTINEAU, S.; DESBIENS, J.-F.; MALO, A. e SIMARD, D. Por uma teoria da pedagogia: pesquisas contemporâneas sobre o saber docente. Trad. Francisco Pereira de Lima. Ijuí: Unijuí, 1998.

LESSARD, Claude; TARDIF, Maurice. Les identities enseignantes: analyse de facteurs de différenciation du corps enseignant québécois 1960- 1990. [S.l.]: Editions du CRP, Université de Sherbrooke, 2003.

MACHADO, Lucília R. S. Diferenciais inovadores na formação de professores da educação profissional. Revista da Educação Brasileira da Educação Profissional e Tecnológica - MEC, SETEC, Brasília, v. 1, n. 1, [jun. 2008].

MACHADO, Lucília Regina de Souza. Politecnia, Escola Unitária e Trabalho. São Paulo: Cortez e Autores Associados, 1989.

MACIEIRA, Daniel de Souza. Limites e possibilidades da formação inicial de professores da educação profissional através do programa especial de formação pedagógica de docentes, segundo as representações de seus egressos. 2009. 209p. Dissertação (Mestrado em Tecnologia) Centro Federal de Educação Tecnológica de Minas Gerais, Belo Horizonte, 2009.

OLIVEIRA, Maria Rita N. S. 20 anos de Endipe. In: Didática, currículo e saberes escolares. Rio de Janeiro: DP\&A, 2000a.

OLIVEIRA, Maria Rita N. S.. Mudanças no mundo do trabalho: acertos e desacertos na proposta curricular para o Ensino Médio (Resolução CNE 03/98). Diferenças entre formação técnica e formação tecnológica. Educação e Sociedade, v. 21, n. 70, p. 4062, 2000.

OLIVEIRA, Maria Rita N. S. Formação e profissionalização dos professores do ensino técnico. In: ARANHA, Antônia V. S.; CUNHA, Daisy M.; LAUDARES, João Bosco. (Org.). Diálogos sobre o trabalbo: perspectivas multidisciplinares. Campinas, SP: Papirus, 2005.

OLIVEIRA, Maria Rita N. S. A formação de professores do ensino técnico. Relatório (Mestrado em Educação Tecnológica) - Centro Federal de Educação Tecnológica de Minas Gerais, Belo Horizonte, 2006.

PETERROSSI, Helena Gemignani. Formação do professor para o ensino técnico. São Paulo: Loyola, 1994.

PIMENTA, S. G. Didática, didáticas específicas e formação de professores: construindo saberes. In: José Carlos Libâneo. (Org.). Concepções e práticas em formação de professores - diferentes olhares. $1^{\mathrm{a}}$ ed. DP\&A: Rio de Janeiro, 2003, v. 1, p. 49-56.

RAMALHO, Betania Leite ; NUÑEZ, Isauro Beltrán ; TERRAZAN, E. ; PRADA, L. E. A. A pesquisa sobre a formação de professores nos programas de pós-graduação em Educação: o caso do ano 2000. In: 25ª Reunião Anual da AMPED - Educação: manifestos, lutas e utopias, 2002, Caxambu - MG, 2002.

SCHON, Donald. Educando o profissional reflexivo: um novo design para o ensino e a aprendizagem. Porto Alegre: Artes Médicas Sul, 2000. 
TANGUY, L. Los conocimientos transmitidos a los futuros obreros. Tempora, [S.1.], v. 1, n. 7, p. 11-28, jan.-jun. 1986.

TARDIFF, Maurice. Saberes docentes e formação profissional. Petrópolis, RJ: Vozes, 2002.

TARDIF, Maurice; LESSARD, Claude. Le travail enseignant au quotidien. Experience, infractions humaines et dilemes professionnels. Europe: DeBoeck, 1999.

ZANTEN, Agnès Van. Abordagens etnográficas em sociologia da educação: escola e comunidade, estabelecimento escolar, sala de aula. In: FORQUIN, Jean Claude (Org). Sociologia da Educação: dez anos de pesquisa. Petrópolis: Vozes, 1995. 


\section{Notas}

1 Sobre a discussão acerca do dualismo estrutural manifesto nas políticas educacionais no Brasil, ver estudos de Frigotto (2003), Machado, (1989) e Cunha (2000).

2 É importante lembrar as considerações feitas por Van Zanten (1995), quando efetua um balanço sobre a produção teórica no campo da Sociologia da Educação na França. Segundo ela, existe uma recusa ou certa ocultação de estudos sobre o ensino técnico. Para Van Zanten, tal descaso seria motivado por uma visão, um tanto apressada, de que a única função do ensino técnico seria ideológica e de relegação.

3 Ver Oliveira (2000).

4 Trata-se das seguintes: banco de dados das bibliotecas do CEFET-MG, da PUC Minas, Unicamp, UFMG e USP; banco de dissertações e teses da Capes e do IBICT; anais do $8^{\circ}$ ao $11^{\circ}$ Endipe e da $19^{\mathrm{a}}$ a $26^{\mathrm{a}}$ reunião anual da AnPED; periódicos da área (Caderno Cedes, Cadernos de Pesquisa, Educação e Pesquisa, Educação em Revista, Educação \& Sociedade, Revista Brasileira de Educação e Educação \& Tecnologia).

5 A temática da formação de professores da Educação Profissional (EP) vem sendo objeto de estudo no âmbito de CEFET-MG. Nessa instituição, já foram concluídos dois projetos de pesquisa: "Vidas de professores da Educação Profissional", financiado pela Fapemig (2005-2007); "A formação de professores para o ensino técnico", financiado pelo CNPq e pela Fapemig (2006-2008). E um terceiro projeto, "Os professores da educação profissional e tecnológica: seus saberes e práticas profissionais", financiado pelo CNPq (2009-2011). Em função dessa trajetória, existe, no CEFETMG, um grupo de pesquisa denominado Forprofet - Formação de Professores da Educação Tecnológica.

6 Definimos alguns códigos para nomear nossos sujeitos de pesquisa: PRF - Professores da Rede Federal de Ensino; PRP - Professores da Rede Privada; e PRE - Professores da Rede Estadual de Ensino.

7 Dado o forte dinamismo das áreas tecnológicas no campo produtivo, os docentes do Ensino Técnico sentem forte necessidade de formação continuada, mas nas áreas específicas de conhecimento em que atuam.

Recebido: 02/08/2010 
